\title{
CHANGE IN UK CONSTRUCTION: MOVING TOWARD SUPPLY CHAIN COLLABORATION
}

\author{
Xianhai MENG \\ School of Planning, Architecture and Civil Engineering, Queen's University Belfast, David Keir Building, \\ Stranmillis Road, BT9 5 AG, Belfast, UK
}

Received 16 Apr. 2011; accepted 17 Oct. 2011

\begin{abstract}
The traditional adversarial relationship in the construction industry has been criticized by a larger number of researchers and practitioners. Following the success of the supply chain collaboration in other industry sectors, such as manufacturing, supply chain relationships in UK construction have been increasingly changing from the traditional adversarial to the collaborative, which is supported by a series of government reports for the industry reform. However, few empirical studies have been conducted to investigate the current status of supply chain relationships in a systematic way. Therefore, there is no clear understanding of how change has taken place in today's practice and whether or not the change is balanced. To bridge the gap, a questionnaire survey is carried out in the UK construction industry. Based on the analysis of more than 100 responses, it is found that the UK construction industry as a whole has experienced an important change and moved toward supply chain collaboration. On the other hand, an unbalance is found for the change movement. In addition to the questionnaire survey, a series of industrial experts are interviewed, which help to explore the specific characteristics of supply chain collaboration in construction and provide practical implications for collaboration strategy implementation.

Keywords: supply chain; relationship; change; collaboration; construction industry; United Kingdom.

Reference to this paper should be made as follows: Meng, X. 2013. Change in UK construction: moving toward supply chain collaboration, Journal of Civil Engineering and Management 19(3): 422-432.
\end{abstract}

\section{Introduction}

Over the years, the construction industry is dominated by the traditional relationship (Humphreys et al. 2003; Pryke 2009). The adversarial nature of this relationship has been criticized by a large number of researchers and practitioners. According to Larson (1997), for example, this relationship is characterized by exploitation, suspicion of each other, ineffective problem solving, and no risk sharing. Similarly, Radziszewska-Zielina (2010) revealed its characteristics, mainly including different aims, win-lose strategy, lack of trust, and limited information flow. The criticisms by other authors, such as Pheng (1999), Rahman and Kumaraswamy (2004), Bennett and Pearce (2006), Bishop et al. (2009), and Xue et al. (2010), also focused on self-interests, different objectives, no mutual benefits, mistrust, communication problem, no rewards for taking risks, and a lack of continuous improvement. Although different terms have been used in these studies, the focuses of their criticisms on the traditional adversarial relationship are nearly the same.
A consensus is that the traditional practice often leads to various problems in construction projects such as claims, conflicts, disputes, low productivity, time delays, cost overruns, quality defects, and customer dissatisfaction. To address the traditional problems, the construction industry must find a way out. The success of the supply chain collaboration in other industry sectors, such as manufacturing, has provided it with an inspiration. Learning from these industry sectors, the UK construction industry has gradually embraced the concept of supply chain collaboration since the end of 1980s (Vrijhoef, Koskela 2000). This is widely recognized as a change movement supported by a series of government reports for the industry reform (Adamson, Pollington 2006; Fernie, Thorpe 2007). The three major reports are Constructing the Team by Sir Michael Latham (1994), Rethinking Construction by Sir John Egan (1998), and Accelerating Change by the Strategic Forum for Construction and chaired by Sir John Egan (2002). A core of the change movement is to replace the traditional adversarial relationship with the collaborative 
relationship. Egan's Accelerating Change report (2002) even set up a strategic goal that $20 \%$ of construction projects by value should be undertaken by integrated and collaborative supply chains by the end of 2004 and this figure should rise to $50 \%$ by the end of 2007 .

The concept of the supply chain collaboration has originated from manufacturing during the $1980 \mathrm{~s}$ (Tan 2001). The adoption of collaborative working as a management strategy has proved to offer great benefits to the parties involved in a supply chain, e.g. improved relationship, reduced cost, enhanced value, and increased satisfaction (Christopher 2005; Emmett, Crocker 2006). This is the reason why supply chain collaboration has been widely accepted in the industry sectors like manufacturing and retailing. Although supply chain collaboration has gained popularity in these industry sectors, there is no generally accepted definition of supply chain collaboration. According to Mentzer et al. (2000), for example, supply chain collaboration means that all companies in the supply chain are actively working together as one toward common objectives. On the other hand, Simatupang et al. (2004) defined supply chain collaboration as two or more independent firms jointly working to align their supply chain processes so as to create value to end customers and stakeholders with greater success than acting alone.

Compared to process-oriented supply chains in manufacturing, supply chains in construction are typically project-based (Cox et al. 2006). A construction supply chain is more complex and involves a larger number of key players, including project client, main contractor, project management consultant, subcontractors, and various suppliers who provide labor, materials, and equipment (LME). Similar to supply chain collaboration in manufacturing and retailing, the increasing acceptance of collaborative working in construction is also due to the identification of its benefits (Akintoye et al. 2000; Chan et al. 2003; Beach et al. 2005). A common understanding of construction researchers and practitioners is that, in order to ensure the success of supply chain collaboration, the most important is to change the roles of the parties involved from adversaries to partners.

In construction, there are various forms of supply chain collaboration such as partnering and alliance (Anvuur, Kumaraswamy 2007; Xue et al. 2010). Many existing studies have identified the key indicators of the collaborative relationship in construction. According to the Trusting the Team report by Bennett and Jayes (1995) from the Reading Construction Forum, for example, the three key features of successful partnering are mutual objectives, problem resolution, and continuous improvement. Similarly, Packham et al. (2003) identified teamwork, trust, and profit sharing as the key elements of collaborative working. The common indicators of the collaborative relationship identified by other studies, such as Pheng (1999), Naoum (2003), Chan et al. (2004), W. T. Chen and T.-T. Chen (2007), and Markert (2011), include common objectives, mutual benefits, trust, clear definition of responsibilities, integrated team working, open communication, effective problem-solving, risk sharing, and continuous improvement. Although no definition is provided in this study for construction supply chain collaboration, it may be more important to identify these key indicators so as to characterize the collaborative relationship. By comparison, the key indicators for the collaborative relationship are identified from a positive perspective while the key indicators for the traditional adversarial relationship are identified from a negative perspective. For example, mutual trust is considered as a basis of collaborative working while suspicion of each other portrays the traditional practice.

Supply chain collaboration can be focused on a single project or based on a series of projects over a specified number of years (Bennett, Pearce 2006; Bygballe et al. 2010). The former is a short-term collaboration and the latter is a long-term collaboration. Long-term collaboration is generally known as strategic partnering or strategic alliance, which requires a long-term commitment (Ingirige, Sexton 2006; Jones, Kaluarachchi 2007). At the initial stage of supply chain management practice, partnering or alliance was always defined as a long-term commitment. According to the UK National Economic Development Council (NEDC 1991), for example, it is only possible to arrange partnering over a long-term period of time rather than during a specific project. In subsequent years, the applicability of short-term collaboration such as project partnering or project alliance has been recognized by more and more construction researchers and practitioners. For example, Humphreys et al. (2003) emphasized that project partnering is a partnering undertaken in a single project, which achieves common objectives but does not involve a long-term commitment. As a result of introducing project partnering or project alliance, more possibilities are provided for supply chain collaboration in construction practice.

Existing construction studies mainly focus on the identification of key relationship indicators and major benefits from the adoption of supply chain collaboration, which may contribute to the encouragement of the industry reform. Although many construction researchers in the UK, such as Fernie and Thorpe (2007), Bresnen (2009) and Gohil et al. (2011), have provided evidence for the successful application of supply chain collaboration through particular case studies, few empirical studies have been conducted to measure the development of supply chain relationships in both breadth and depth. The limitation of existing studies forms a barrier to get a thorough 
understanding of the change movement in UK construction. Therefore, there is a need for a systematic investigation of supply chain relationships in today's practice. In this study, a questionnaire survey and a series of expert interviews are carried out in the UK. The purpose of this study is to analyze the trend toward supply chain collaboration and explore the specific characteristics of collaborative working in construction. All these provide an insight into the strategic development of the construction industry.

\section{Research methods}

A combination of a literature review, a questionnaire survey, and expert interviews is adopted in this study, which starts with a comprehensive literature review. The review of relevant literature establishes a good basis for this study because it (1) provides an upto-date understanding of the industry development, (2) identifies the need for the current research, and (3) defines the key indicators of supply chain relationships. The common relationship indicators identified from both positive and negative perspectives are: definition of roles and responsibilities, mutual objectives, trust, joint working, communication, problem solving, benefit/risk sharing, and continuous improvement. "Benefit/risk sharing" here covers the meanings of both mutual benefits and shared risks. The key relationship indicators identified describe a supply chain relationship in eight dimensions or key areas. They are used in this study to measure supply chain relationships in construction projects.

This empirical study attempts to analyze the trend toward supply chain collaboration in UK construction by answering the research questions concerning (1) whether there is enough evidence for the change from the traditional adversarial to the collaborative relationships, (2) whether change in relationship has taken place in a balanced way, (3) in which sectors supply chain collaboration is more commonly seen, (4) which relationship areas perform better than others, (5) what relationship areas are still problematic so that there is a need for further change, (6) which part of a supply chain is more likely to be affected by the old culture so that more emphasis should be placed on its relationship improvement, and (7) whether relationship can be significantly improved by adopting collaborative working approaches. A questionnaire survey is undertaken in this research to answer these questions. It is a project-specific investigation mainly focusing on building projects completed in the UK. Respondents were asked to fill in the questionnaire based on the projects in which they participated and the parts of supply chains in which they were involved. The survey covers both the traditional and collaborative supply chains in construction.
The development of the questionnaire (see Appendix 1) is based on the key relationship indicators identified from the literature review. A total of eight questions are designed to rate a respondent's perceptions of a supply chain relationship in terms of a fourpoint Likert scale $(1=$ Strongly Agree; $2=$ Agree; $3=$ Disagree; and $4=$ Strongly Disagree). For example, the question about "Communication" is: Communication between the parties was open and effective, do you agree? In addition to these eight questions, some other questions are developed to collect the information about a project and a respondent, e.g. the type of a project, the organization nature of a respondent, and the application of collaboration.

A five-point scale is often used in a questionnaire. However, this does not necessarily mean that it is not possible to use other scales. According to Frankfort-Nachmias and Nachmias (2008), sometimes a three, four, six, or seven-point scale can be used for a questionnaire. Instead of a five-point scale, a four-point scale is adopted in this study, with which a response of Strongly Agree or Agree to a relationship indicator describes a collaborative relationship area while a response of Disagree or Strongly Disagree to a relationship indicator characterizes a traditional relationship area. If a five-point scale was adopted, neither Agree nor Disagree or Uncertain would be provided. For a supply chain relationship, such a response does not make sense. This is why a four-point scale is designed in this study, by which the respondent has to select one of the four relationship levels.

A pilot study was conducted before the formal survey. The purpose of the pilot study is to validate the initial questionnaire, check its applicability, and obtain the feedbacks in order to make refinement. The formal survey mainly targeted the key players involved in a construction supply chain, such as project client, main contractor, and project management consultant, because they represent the core of the whole supply chain, especially client-main contractor relationship is regarded by Cox et al. (2006) as the main relationship in a construction supply chain. On the other hand, some representatives from subcontractors and LME suppliers were also involved.

In order to ensure a representative sample, the potential respondents were required to have sufficient experience in project management and relationship management, and hold key positions in relation to project management and relationship management in their organizations, such as managing director, procurement manager, commercial manager, project manager, contract manager, consulting engineer, and quantity surveyor. Around 400 industrial experts were selected as potential respondents from expert databases and other available sources. The expert databases in this study were based on the individual memberships of industry organizations and professional bodies such 
as the Constructing Excellence. The sample provided a good representation of supply chain management professionals in the UK construction industry.

The questionnaire was sent to the potential respondents through both email and post. Generally, post was used for data collection only when the email address of a potential respondent was not available. A cover letter was attached as an introduction to the questionnaire, explaining the focus, target, purpose, and confidentiality of the research and expressing appreciation as well. As a result of the survey, around 350 questionnaires were delivered to the potential respondents and 106 completed questionnaires were returned with a response rate of $30.3 \%$, among which $40(37.7 \%)$ responses were collected from client organizations, $32(30.2 \%)$ from main contractors, $22(20.8 \%)$ from project management consultants, and $12(11.3 \%)$ from subcontractors and LME suppliers.

As a quantitative research method, the questionnaire survey is popular because it is easy to get information from many people (Gillham 2000). On the other hand, the interview is a good way of accessing people's knowledge, understandings, interpretations, and experiences (Mason 2002). This qualitative research method takes full advantage of the direct interaction with people (Seale 2004). Compared to collecting questionnaire responses, interviewing experts is more in-depth (Marshall, Rossman 2006). Subsequent to the questionnaire survey in this study, around 20 construction supply chain management experts were further interviewed face-to-face and one-by-one. The purpose of semi-structured interviews is to find in-depth evidence for the change movement and examine construction practitioners' views and concerns with supply chain collaboration. Combined with the questionnaire survey, the expert interviews describe a clearer picture for the industry development. The combination of quantitative and qualitative methods also provides higher reliability and greater validity for the research.

\section{Analysis of questionnaire results}

The empirical data collected from the questionnaire survey are analyzed statistically in the following. The data analysis is made in a comparative way, which uncovers the relationship progress and identifies any unsolved problems.

\subsection{Information of projects}

First of all, the project information is reported as follows:

- Type of project: of the 106 responses, 18 $(17.0 \%)$ are school buildings, $16(15.1 \%)$ are residential buildings, $14(13.2 \%)$ are university buildings, $11(10.4 \%)$ are commercial buildings,
$9(8.5 \%)$ are hospital and health care buildings, $9(8.5 \%)$ are office buildings, $4(3.8 \%)$ are sport facilities, $3(2.8 \%)$ are industrial buildings, 3 $(2.8 \%)$ are government buildings such as city hall, court, and prison, and $11(10.4 \%)$ represent other types of buildings such as airport terminals and military training buildings. The responses cover almost all typical building projects. In addition, 8 civil engineering projects such as road and bridge are reported, which account for $7.5 \%$ in the survey sample;

- Application of supply chain collaboration: short-term collaboration exists in 30 surveyed projects $(28.3 \%)$ and long-term collaboration presents in 41 surveyed projects (38.7\%). On the other hand, the traditional approach is used in 35 surveyed projects $(33.0 \%)$. The responses span over the whole relationship spectrum.

\subsection{Achievement of Egan's strategic goal}

If both short-term and long-term collaborative relationships are taken into account, there are $67.0 \%$ of the surveyed projects in which supply chain collaboration is adopted. For almost all types of projects, as seen in Table 1, the proportion of supply chain collaboration is not less than 50\%. Industrial buildings are the only exception. The finding suggests that on the whole the strategic goal set up by Egan's Accelerating Change report (Egan 2002) has been achieved and supply chain collaboration has become prevalent in today's construction practice. Since the emergence of the current economic recession starting from the end of 2007, no government reports have been further published to promote supply chain collaboration. Even so, the achievement of Egan's strategic goal at the end of 2007 demonstrates a significant change in the UK construction industry.

Compared to short-term collaboration, longterm collaboration is more commonly used in almost all types of projects. For example, $33.3 \%$ of school building projects adopt long-term collaboration while $22.2 \%$ of such projects choose short-term collaboration. Only for university buildings and sport facilities, short-term collaboration is found to be more frequent than long-term collaboration. The wide acceptance of long-term collaboration is because the parties involved benefit more from its continuing and stable relationship, which will be further discussed when analyzing interview results.

If further analysis is made, the traditional approach, short-term collaboration, and long-term collaboration can be found in almost all sectors (see Table 1). By comparison, collaborative working is more popular in the health care and housing sectors. For hospital and health care buildings, all the surveyed projects adopt either short-term or longterm collaborations. On the other hand, only $6.3 \%$ of 
Table 1. Application of supply chain collaboration by sectors

\begin{tabular}{|c|c|c|c|c|}
\hline Type of building & $\begin{array}{l}\text { Traditional approach } \\
\qquad \mathrm{n}=35\end{array}$ & $\begin{array}{l}\text { Short-term collaboration } \\
\qquad \mathrm{n}=30\end{array}$ & $\begin{array}{l}\text { Long-term collaboration } \\
\qquad \mathrm{n}=41\end{array}$ & Total \\
\hline School building & $8(44.4 \%)$ & $4(22.2 \%)$ & $6(33.3 \%)$ & 18 \\
\hline Residential building & $1(6.3 \%)$ & $7(43.8 \%)$ & $8(50.0 \%)$ & 16 \\
\hline University building & $7(50.0 \%)$ & $5(35.7 \%)$ & $2(14.3 \%)$ & 14 \\
\hline Commercial building & $5(45.5 \%)$ & $2(18.2 \%)$ & $4(36.4 \%)$ & 11 \\
\hline Hospital and health care building & $0(0.0 \%)$ & $2(22.2 \%)$ & $7(77.8 \%)$ & 9 \\
\hline Office building & $3(33.3 \%)$ & $2(22.2 \%)$ & $4(44.4 \%)$ & 9 \\
\hline Sport facility & $1(25.0 \%)$ & $2(50.0 \%)$ & $1(25.0 \%)$ & 4 \\
\hline Government building & $1(33.3 \%)$ & $1(33.3 \%)$ & $1(33.3 \%)$ & 3 \\
\hline Industry building & $3(100.0 \%)$ & $0(0.0 \%)$ & $0(0.0 \%)$ & 3 \\
\hline Civil engineering & $3(37.5 \%)$ & $2(25.0 \%)$ & $3(37.5 \%)$ & 8 \\
\hline Other building & $3(27.3 \%)$ & $3(27.3 \%)$ & $5(45.5 \%)$ & 11 \\
\hline
\end{tabular}

residential building projects in the survey still use the traditional approach. The finding provides evidence for the wide acceptance of supply chain collaboration in these two sectors. In the UK, the National Health Services (NHS) represents the public health care system, which provides the vast majority of health care services in the whole country. Housing is divided into public, private, and social housing, in which social housing is developed by housing associations for low-income families. In recent years, there is an increasing emphasis on supply chain management from the NHS and housing systems, especially social housing, in order to increase value for money and achieve best practice, explaining the reason why collaborative working is predominant in the health care and housing sectors.

\subsection{Assessment of relationship}

For the 106 projects surveyed, the rating of relationships in the eight key areas are summarized in Table 2 where SA stands for Strongly Agree, A for Agree, D for Disagree, and SD for Strongly Disagree.

Since the questions related to eight relationship indicators are all asked in a positive way, the smaller the mean value, the more collaborative the relationship is in a certain area. As a result, the ranking of the means for the answers to eight relationship questions is listed in Table 2. The top four areas are "definition of roles and responsibilities", "communication", "joint working", and "problem solving", all of which have received more than $80.0 \%$ of positive responses (Agree and Strongly Agree). On the other hand, "trust", "mutual objectives", and "continuous improvement" rank from fifth to seventh. By comparison, clear definition of roles and responsibilities, open communication, joint working, and effective problem solving are more likely to implement while continuous improvement, mutual objectives and high degree of trust are less likely to achieve. Even so, the positive responses to "trust", "mutual objectives", and "continuous improvement" are all greater than $70.0 \%$. The finding indicates that looking at most of the key relationship areas the construction industry as a whole has been changed from the traditional adversarial to the collaborative. However, there may still remain unsolved problems in some construction projects.

Negative responses cover both Disagree and Strongly Disagree. The negative responses to "continuous improvement", "trust", and "mutual objectives" are found in $26.7 \%, 23.6 \%$, and $21.0 \%$ of the surveyed projects, respectively. Mutual objectives are widely recognized as a fundamental element of supply chain collaboration (Crespin-Mazet, Portier 2010). The lack of mutual objectives implies that the parties involved in a supply chain concentrate on their own objectives and make efforts in different directions.

Table 2. Rating of key relationship indicators

\begin{tabular}{|c|c|c|c|c|c|c|c|}
\hline Key relationship indicator & SA & A & $\mathrm{D}$ & SD & Mean & Std. dev. & Rank \\
\hline Definition of roles and responsibilities & $20.4 \%$ & $67.0 \%$ & $12.6 \%$ & $0.0 \%$ & 1.92 & 0.572 & 1 \\
\hline Mutual objectives & $8.6 \%$ & $70.5 \%$ & $20.0 \%$ & $1.0 \%$ & 2.13 & 0.556 & 6 \\
\hline Trust & $14.7 \%$ & $61.8 \%$ & $21.6 \%$ & $2.0 \%$ & 2.11 & 0.659 & 5 \\
\hline Joint working & $15.7 \%$ & $71.6 \%$ & $11.8 \%$ & $1.0 \%$ & 1.98 & 0.563 & 3 \\
\hline Communication & $22.1 \%$ & $61.5 \%$ & $15.4 \%$ & $1.0 \%$ & 1.95 & 0.644 & 2 \\
\hline Problem solving & $16.3 \%$ & $68.3 \%$ & $14.4 \%$ & $1.0 \%$ & 2.00 & 0.591 & 4 \\
\hline Benefit/risk sharing & $7.9 \%$ & $19.8 \%$ & $54.5 \%$ & $17.8 \%$ & 2.82 & 0.817 & 8 \\
\hline Continuous improvement & $8.9 \%$ & $64.4 \%$ & $25.7 \%$ & $1.0 \%$ & 2.19 & 0.595 & 7 \\
\hline
\end{tabular}


Trust is an important indicator for supply chain relationships (Davis, Walker 2009). When the level of mutual trust is quite low, the parties are defensive against each other, and therefore it is not possible for them to collaborate together. In order to create value for the project, all parties involved should commit to continuous improvement (Smyth 2010). The absence of continuous improvement will lead to low efficiency, unnecessary waste, and poor performance. As a result, it casts blight on project success.

Fair gain or loss sharing ensures that supply chain partners closely collaborate with each other (Meng et al. 2011). In this study, however, "benefit/ risk sharing" performs poorest in terms of relationship because the greatest number of negative responses is found in this area and $72.3 \%$ of the surveyed projects lack benefit/risk sharing between the parties. The finding reveals that compared to the other seven areas benefit/risk sharing is most difficult to achieve in reality, and the unwillingness to share benefits and risks still dominates most of today's construction projects. The poor presentation of "benefit/risk sharing" provides a remarkable contrast to relationship development in the other seven areas. The gap reflects the unbalance of the change movement, demonstrating that the relationship progress in some particular areas is much slower than in other areas. This phenomenon can be explained from two sides. On one hand, the construction industry as a whole has started its journey to supply chain collaboration. On the other hand, inherent problems are still the obstacles to the change agenda. There is no doubt that benefit/risk sharing is the biggest challenge to supply chain collaboration in construction, and therefore more efforts are needed to encourage the shared culture in the whole industry.

\subsection{Comparison between three working approaches}

Supply chain relationships in construction are quite diverse. Three distinct forms of working styles are the traditional approach, short-term collaboration, and long-term collaboration. Based on the empirical data collected from the questionnaire survey, the means of eight relationship indicators are compared between the three groups. As shown in Table 3, the means in the eight key areas for the traditional approach, short-term collaboration, and long-term collaboration are ranked in descending order. For example, the mean values of "trust" in the three groups are 2.33 for the traditional approach, 2.07 for short-term collaboration, and 1.95 for long-term collaboration. The finding provides quantitative evidence to conclude that in terms of relationship short-term collaboration is better than the traditional approach, and long-term collaboration is better than short-term collaboration. By adopting short-term and long-term collaborations, supply chain relationships will be improved step-by-step. As a result, the definition of one traditional approach and two collaborative working approaches describes a step-wise evolutionary path across the whole relationship spectrum.

One-way analysis of variance (ANOVA) is further made to test whether the mean values in each relationship area are equal or not between the three groups. The results of $F$-statistics and significance level show that there are significant differences between the three groups at the 0.05 level in seven areas and at the 0.01 level in one area. The finding indicates that relationship improvement in all key areas is significant when moving from the traditional approach through short-term collaboration to longterm collaboration. Although "benefit/risk sharing" is most unsatisfactory in the eight relationship areas, sharing between the parties will be significantly increased when the traditional practice is replaced with collaborative working approaches. On the other hand, the most significant difference is found at the 0.01 level for the mean values of "problem solving" between the three groups. As a result, adopting collaborative working approaches has the greatest effect on effective problem solving compared to relationship improvement in the other seven areas.

Table 3. Means comparison between three working approaches

\begin{tabular}{|c|c|c|c|c|c|}
\hline \multirow[b]{2}{*}{ Key relationship indicator } & \multirow{2}{*}{$\begin{array}{l}\text { Traditional approach } \\
\qquad \mathrm{n}=35\end{array}$} & \multirow{2}{*}{$\begin{array}{l}\text { Short-term collaboration } \\
\qquad \mathrm{n}=30\end{array}$} & \multirow{2}{*}{$\begin{array}{l}\text { Long-term collaboration } \\
\qquad \mathrm{n}=41\end{array}$} & \multicolumn{2}{|c|}{$\begin{array}{l}\text { One-way } \\
\text { ANOVA }\end{array}$} \\
\hline & & & & $F$ & Sig. \\
\hline $\begin{array}{l}\text { Definition of roles and } \\
\text { responsibilities }\end{array}$ & 2.09 & 1.96 & 1.76 & 3.377 & 0.038 \\
\hline Mutual objectives & 2.31 & 2.14 & 1.98 & 3.687 & 0.028 \\
\hline Trust & 2.33 & 2.07 & 1.95 & 3.277 & 0.042 \\
\hline Joint working & 2.19 & 2.00 & 1.80 & 4.469 & 0.014 \\
\hline Communication & 2.09 & 2.07 & 1.76 & 3.271 & 0.042 \\
\hline Problem solving & 2.24 & 2.00 & 1.80 & 5.341 & 0.006 \\
\hline Benefit/risk sharing & 3.12 & 2.72 & 2.64 & 3.548 & 0.033 \\
\hline Continuous improvement & 2.38 & 2.21 & 2.02 & 3.232 & 0.044 \\
\hline
\end{tabular}




\subsection{Comparison between upstream and downstream supply chains}

As mentioned above, this survey mainly focused on upstream relationships between client, main contractor, and project management consultant. All responses from client, main contractor, and project management consultant organizations were related to different upstream relationships in their supply chains. An upstream supply chain consists of client-main contractor, client-consultant, and consultant-main contractor relationships. Generally, client-main contractor relationship is regarded as the main relationship in a supply chain. In order to collect the information about downstream relationships, some representatives of subcontractors and LME suppliers were also involved in the questionnaire survey. A downstream supply chain includes main contractorsubcontractor, main contractor-LME supplier and subcontractor-LME supplier relationships. By doing so, a brief comparison is made between upstream and downstream supply chains.

Based on the analysis, an asymmetry is identified between upstream and downstream relationships. Upstream relationships in all eight areas are better than downstream relationships. The mean values of eight relationship indicators for upstream relationships are $1.91,2.12,2.09,1.98,1.92,1.98,2.80$, and 2.18 , while those for downstream relationships are 2.00, 2.27, $2.33,2.00,2.18,2.18,3.00$, and 2.27. The finding reinforces some previous studies such as Dainty et al. (2001) and Mason (2007) by providing them with quantitative evidence. The analysis result suggests that the downstream side is relatively slow to adopt supply chain collaboration as a management strategy. Although downstream supply chains carry out the majority of construction work, so far less emphasis has been placed on the improvement of their relationships. The improvement of upstream relationships is just a starting point. In order to take supply chain collaboration one step further, it is crucial to pass the collaborative spirit downstream.

\section{Analysis of interview results}

Subsequent to the questionnaire survey, around 20 supply chain management experts were further interviewed in this study. The interviewees represented different types of construction organizations in upstream and downstream supply chains. The interviewees representing client organizations were selected from public and private sectors. The roles of the interviewees in their organizations were placed at different levels from general directors to project managers. All of them had over 10 years of working experience in the industry. In addition to the industrial interviewees, a small number of academic researchers were also interviewed. The expert interviews provided in-depth evidence for the successful application of supply chain collaboration in the UK construction industry. In the public sector, construction supply chain collaboration is mostly used in the NHS estates, social housing projects, local authority schools, and the Ministry of Defence (MOD) estates. In the private sector, collaborative working has been widely accepted by supermarket retailers, private banks, and the British Airports Authority (BAA) in their construction projects. According to the interviewees, the common features of these sectors are that clients can provide continuity of work and people have recognized the importance of making change in their relationships. On the other hand, there are some differences between public and private sector collaboration. Public sector clients are encouraged to use collaborative working for value for money. They are more likely to get public funding if they adopt the strategy of supply chain collaboration. By comparison, private sector clients usually use collaborative working when they can see commercial benefits, e.g. quicker investment return based on faster project delivery.

According to the interviewees in this study, supply chain collaboration is mainly suitable for a long-term program because it offers a stable business relationship, from which the partners can benefit more. From the contractor perspective, continuity of work is the most important benefit. Supply chain collaboration based on a long-term program requires continuity of work provided by the client. For this reason, it is only possible for repeat clients to pursue long-term collaboration. However, this does not necessarily mean that the principle of collaborative working cannot be followed in a single project. In construction, many clients are one-off. For these clients, short-term collaboration is still better than the traditional practice. Another important finding during the expert interviews is that project-specific collaboration is often used by a repeat client as a trial run when working with a contractor for the first time. Once they have successful cooperation experience in the project and establish mutual trust, they may enter into a long-term program. The finding provides a better understanding of the suitability of different types of collaborative working approaches and contributes to distinguishing the role of short-term collaboration from that of long-term collaboration.

As mentioned above, client-main contractor relationship is upstream while main contractor-subcontractor/supplier relationship is downstream in a construction supply chain. The interviewees agreed that the current focus of supply chain collaboration is on the client-main contractor relationships. On the other hand, most of the main contractor-subcontractor/supplier relationships are still traditional, which supports the finding of the questionnaire result 
analysis. During the interviews, some client and subcontractor representatives pointed out that collaborative working between clients and subcontractors may be more successful. The finding is consistent with Dainty et al. (2001) and Davey et al. (2001). From the perspective of subcontractors, a direct link with clients can create more work opportunities and ensure more reliable payment. If a direct link is established, clients are more likely to achieve value for money by taking full advantage of subcontractors' expertise. At the same time, they do not need to employ and pay main contractors. Although the interviewees provided some evidence for the successful collaboration between clients and subcontractors, clients need to have enough capabilities of project management in order to work with subcontractors directly. In general, oneoff clients are inexperienced in project management and should be very careful for applying this approach.

Subcontractors and LME suppliers represent small- and medium-sized enterprises (SMEs). The interviewees believed that less collaboration in downstream supply chains are mainly because many main contractors are still reluctant to abandon the traditional practice and subcontractors are skeptical about their benefits from collaborating with main contractors. For example, the lowest price is still often considered by many main contractors in the UK as the primary criterion to select their subcontractors, which may be different from the common use of multicriteria subcontractor selection in international projects as reported by Ulubeyli et al. (2010). In a construction supply chain, the main contractor is in a position that links the upstream client and the downstream subcontractors. Main contractors represent medium- to large-scale construction companies. For the client, the main contractor is a supplier, while for subcontractors the main contractor is a customer. Therefore, the main contractor plays a pivotal role in passing the collaborative spirit on to the whole supply chain. Some interviewees from main contractors stated that a supply chain manager is specifically appointed in their organizations, which is responsible for the development of supply chain management strategies and the communication with both their customers and their suppliers. This news is quite inspiring because it reflects the fact that main contractors have paid greater attention to supply chain collaboration with both upstream and downstream partners than ever before. Only if the majority of main contractors recognize the importance of the involvement of subcontractors and LME suppliers to their business success is it possible to extend collaborative working into downstream supply chains.

\section{Conclusions}

This empirical study adopts a combination of quantitative and qualitative methodologies. The analysis of empirical data shows that a significant change has been made in the UK construction industry to replace the traditional adversarial relationship with the collaborative relationship. The trend toward supply chain collaboration is characterized by: (1) the wide recognition of the importance of supply chain collaboration in the industry; (2) the support from the UK government; (3) the wide acceptance of collaborative working as a management strategy; and (4) an unbalance of relationship development. According to the comparative analysis in this study, existing supply chain relationships perform differently in terms of project sectors, relationship areas and supply chain sides because (1) supply chain collaboration and partnering is more commonly seen in the sectors where continuity of work can be provided; (2) benefit/risk sharing is much more difficult to come true compared to the other relationship indicators; and (3) downstream supply chains are more traditional than upstream supply chains. By comparison, long-term collaboration offers greater benefits, and continuity of work enables a long-term business relationship to be established. This is a reasonable explanation of why there is more evidence for supply chain collaboration in the sectors where client organizations have continuous work opportunities. On the other hand, unsolved problems such as the lack of benefit/risk sharing and the downstream resistance to collaborative working reveal that although the construction industry as a whole has increasingly adopted the concept of supply chain collaboration the full embrace of this innovative approach is subject to the inertia of the old culture. Therefore, there is a need to call for further change.

Generally, clients are the initiators of supply chain collaboration. For this reason, collaborative working is often experienced between clients and main contractors today in upstream supply chains. Compared to upstream supply chains, both main contractors and subcontractors in the majority of downstream supply chains still hesitate to collaborate with each other. This finding is consistent with the conclusions of some early studies on subcontractors' views and experiences. Going beyond the limitations of early studies, this research makes a quantitative comparison between upstream and downstream relationships. All studies have their limitations, and this research is not exceptional. A major limitation of this research is that only a small number of questionnaire responses have been collected from downstream supply chains. As a result, upstream and downstream relationships can only be compared briefly. Further research can be outlined to collect more empirical data from downstream supply chains and make accurate analysis. Unlike client-main contractor relationship in the upstream side, a main contractor works with many SMEs in the downstream side. Due to the specific 
characteristics of downstream supply chains, it may not be appropriate for main contractors and subcontractors/suppliers to simply imitate the collaboration working approaches used between clients and main contractors. For this reason, another focus of further research is to look for more suitable approaches for downstream supply chain collaboration.

\section{Acknowledgements}

The author would like to express his gratitude to the anonymous questionnaire respondents and interviewees who participated in this research. In addition, the author would like to thank the anonymous reviewers and the editors for their efforts and supports.

\section{References}

Adamson, D. M.; Pollington, T. 2006. Change in the construction industry: an account of the UK construction industry reform movement 1993-2003. Oxon: Routledge. 192 p.

Akintoye, A.; McIntosh, G.; Fitzgerald, E. 2000. A survey of supply chain collaboration and management in the UK construction industry, European Journal of Purchasing \& Supply Management 6(3-4): 159-168. http://dx.doi.org/10.1016/S0969-7012(00)00012-5

Anvuur, A. M.; Kumaraswamy, M. M. 2007. A conceptual model of partnering and alliancing, Journal of Construction Engineering and Management ASCE 133(3): 225234.

http://dx.doi.org/10.1061/(ASCE)0733-9364(2007) 133:3(225)

Beach, R.; Webster, M.; Campbell, K. M. 2005. An evaluation of partnership development in the construction industry, International Journal of Project Management 23(8): 611-621.

http://dx.doi.org/10.1016/j.ijproman.2005.04.001

Bennett, J.; Jayes, S. 1995. Trusting the team: the best practice guide to partnering in construction. Reading: Reading Construction Forum. 82 p.

Bennett, J.; Pearce, S. 2006. Partnering in the construction industry: code of practice for strategic collaborative working. Oxford: Butterworth-Heinemann. 288 p.

Bishop, D.; Felstead, A.; Fuller, A.; Jewson, N.; Unwin, L.; Kakavelakis, K. 2009. Constructing learning: adversarial and collaborative working in the British construction industry, Journal of Education and Work 22(4): 243-260.

http://dx.doi.org/10.1080/13639080903290355

Bresnen, M. 2009. Living the dream? Understanding partnering as emergent practice, Construction Management and Economics 27(10): 923-933. http://dx.doi.org/10.1080/01446190902974145

Bygballe, L. E.; Jahre, M.; Swärd, A. 2010. Partnering relationships in construction: a literature review, Journal of Purchasing and Supply Management 16(4): 239-253. http://dx.doi.org/10.1016/j.pursup.2010.08.002

Chan, A. P. C.; Chan, D. W. M.; Ho, K. S. K. 2003. An empirical study of the benefits construction partnering in Hong Kong, Construction Management and Economics
21(5): 523-533.

http://dx.doi.org/10.1080/0144619032000056162

Chan, A. P. C.; Chan, D. W. M.; Chiang, Y. H.; Tang, B. S.; Chan, E. H. W.; Ho, K. S. K. 2004. Exploring critical success factors for partnering in construction projects, Journal of Construction Engineering and Management ASCE 130(2): 188-198.

http://dx.doi.org/10.1061/(ASCE)0733-9364(2004) 130:2(188)

Chen, W. T.; Chen, T.-T. 2007. Critical success factors for construction partnering in Taiwan, International Journal of Project Management 25(5): 475-484. http://dx.doi.org/10.1016/j.ijproman.2006.12.003

Christopher, M. 2005. Logistics and supply chain management: creating value-adding networks. 3rd ed. Harlow: Pearson. 305 p.

Cox, A.; Ireland, P.; Townsend, M. 2006. Managing in construction supply chains and markets. London: Thomas Telford. 293 p.

Crespin-Mazet, F.; Portier, P. 2010. The reluctance of construction purchasers towards project partnering, Journal of Purchasing and Supply Management 16(4): 230-238. http://dx.doi.org/10.1016/j.pursup.2010.06.001

Dainty, A. R. J.; Briscoe, G. H.; Millett, S. J. 2001. Subcontractor perspectives on supply chain alliances, Construction Management and Economics 19(8): 841848.

http://dx.doi.org/10.1080/01446190110089727

Davey, C. L.; Lowe, D. J.; Duff, A. R. 2001. Generating opportunities for SMEs to develop partnerships and improve performance, Building Research and Information 29(1): 1-11. http://dx.doi.org/10.1080/09613210150208741

Davis, P. R.; Walker, D. H. T. 2009. Building capability in construction projects: a relationship-based approach, Engineering, Construction and Architectural Management 16(5): 475-489.

http://dx.doi.org/10.1108/09699980910988375

Egan, J. 1998. Rethinking construction. London: Department of Environment, Transport and Regions. $37 \mathrm{p}$.

Egan, J. 2002. Accelerating change. London: Strategic Forum for Construction. $44 \mathrm{p}$.

Emmett, S.; Crocker, B. 2006. The relationship-driven supply chain: creating a culture of collaboration throughout the chain. Aldershot: Gower. 180 p.

Fernie, S.; Thorpe, A. 2007. Exploring change in construction: supply chain management, Engineering, Construction and Architectural Management 14(4): 319333.

http://dx.doi.org/10.1108/09699980710760649

Frankfort-Nachmias, C.; Nachmias, D. 2008. Research methods in the social sciences. 7th ed. New York: Worth. 376 p.

Gillham, B. 2000. Developing a questionnaire. London: Continuum. $104 \mathrm{p}$.

Gohil, U.; Carrillo, P.; Ruikar, K.; Anumba, C. 2011. Valueenhanced collaborative working: case study of a small management advisory firm, Construction Innovation: Information, Process, Management 11(1): 43-60. http://dx.doi.org/10.1108/14714171111104628

Humphreys, P.; Matthews, J.; Kumaraswamy, M. 2003. Preconstruction project partnering: from adversarial to 
collaborative relationships, Supply Chain Management: an International Journal 8(2): 166-178. http://dx.doi.org/10.1108/13598540310468760

Ingirige, B.; Sexton, M. 2006. Alliances in construction: investigate initiatives and barriers for long-term collaboration, Engineering, Construction and Architectural Management 13(5): 521-535. http://dx.doi.org/10.1108/09699980610690774

Jones, K.; Kaluarachchi, Y. 2007. Operational factors affecting strategic partnering in UK social housing, Engineering, Construction and Architectural Management 14(4): 334-345. http://dx.doi.org/10.1108/09699980710760658

Larson, E. 1997. Partnering on construction projects: a study of the relationship between partnering activities and project success, IEEE Transactions on Engineering Management 44(2): 188-195. http://dx.doi.org/10.1109/17.584926

Latham, M. 1994. Constructing the team. London: Her Majesty's Stationary Office. 54 p.

Markert, C. D. 2011. Partnering: what must be done to avoid failure, Leadership and Management in Engineering ASCE 11(2): 155-161. http://dx.doi.org/10.1061/(ASCE)LM.1943-5630. 0000115

Marshall, C.; Rossman, G. 2006. Designing qualitative research. 4th ed. London: SAGE. $344 \mathrm{p}$.

Mason, J. 2002. Qualitative researching. 2nd ed. London: SAGE. 224 p.

Mason, J. R. 2007. The views and experiences of specialist contractors on partnering in the UK, Journal of Construction Management and Economics 25(5): 519527. http://dx.doi.org/10.1080/01446190701326828

Meng, X.; Sun, M.; Jones, M. 2011. Maturity model for supply chain relationships in construction, Journal of Management in Engineering ASCE 27(2): 97-105. http://dx.doi.org/10.1061/(ASCE)ME.1943-5479. 0000035

Mentzer, J. T.; Foggin, J. H.; Golicic, S. L. 2000. Collaboration: the enablers, impediments and benefits, Supply Chain Management Review 4(4): 52-58.

Naoum, S. 2003. An overview into the concept of partnering, International Journal of Project Management 21(1): 71-76. http://dx.doi.org/10.1016/S0263-7863(01)00059-X

National Economic Development Council (NEDC) 1991. Partnering: contracting without conflict. London: NEDC. 118 p.

Packham, G.; Thomas, B.; Miller, C. 2003. Partnering in the house building sector: a subcontractor's view, International Journal of Project Management 21(5): 327-332. http://dx.doi.org/10.1016/S0263-7863(02)00046-7
Pheng, L. S. 1999. The extension of construction partnering for relationship marketing, Marketing Intelligence \& Planning 17(3): 155-162. http://dx.doi.org/10.1108/02634509910271614

Pryke, S. 2009. Construction supply chain management: concepts and case studies. London: Wiley-Blackwell. $230 \mathrm{p}$.

Radziszewska-Zielina, E. 2010. Methods for selecting the best partner construction enterprise in terms of partnering relations, Journal of Civil Engineering and Management 16(4): 510-520. http://dx.doi.org/10.3846/jcem.2010.57

Rahman, M. M.; Kumaraswamy, M. M. 2004. Contracting relationship trends and transitions, Journal of Management in Engineering ASCE 20(4): 147-161.

http://dx.doi.org/10.1061/(ASCE)0742-597X(2004) 20:4(147)

Seale, C. 2004. Social research methods: a reader. London: Routledge. 560 p.

Simatupang, T. M.; Wright, A. C.; Sridharan, R. 2004. Applying the theory of constraints to supply chain collaboration, Supply Chain Management: an International Journal 9(1): 57-70. http://dx.doi.org/10.1108/13598540410517584

Smyth, H. 2010. Construction industry performance improvement programmes: the UK case of demonstration projects in the 'Construction Improvement' programme, Construction Management and Economics 28(3): 255-270.

http://dx.doi.org/10.1080/01446190903505948

Tan, K. C. 2001. A framework of supply chain management literature, European Journal of Purchasing \& Supply Management 7(1): 39-48. http://dx.doi.org/10.1016/S0969-7012(00)00020-4

Ulubeyli, S.; Manisali, E.; Kazaz, A. 2010. Subcontractor selection practices in international construction projects, Journal of Civil Engineering and Management 16(1): 47-56. http://dx.doi.org/10.3846/jcem.2010.04

Vrijhoef, R.; Koskela, L. 2000. The four roles of supply chain management in construction, European Journal of Purchasing \& Supply Management 6(3-4): 169-178. http://dx.doi.org/10.1016/S0969-7012(00)00013-7

Xue, X.; Shen, Q.; Ren, Z. 2010. Critical review of collaborative working in construction projects: business environment and human behaviors, Journal of Management in Engineering ASCE 26(4): 196-208. http://dx.doi.org/10.1061/(ASCE)ME.1943-5479. 0000025

Xianhai MENG. Dr, currently a lecturer in construction and project management at Queen's University Belfast, UK. Previously he was an associate professor at Tsinghua University, Beijing, China. His research interests include project management, supply chain management, performance measurement and improvement, procurement and contract strategies, construction economics and finance, and public-private partnerships. 


\section{Appendix 1: Questionnaire for supply chain relationships in construction}

\section{Information about project and respondent}

\subsection{What is the nature of your organization?}

$\square$ Project client

$\square$ Main contractor

$\square$ Project management consultant

$\square$ Subcontractor

$\square$ Labor, materials and equipment supplier

$\square$ Others, please specify

1.2. What type of building project did you participate in?

$\square$ Office building

$\square$ Hospital building

$\square \quad$ School building

$\square \quad$ Residential building

$\square$ Commercial building

$\square$ Others, please specify

\subsection{Which part of supply chain were you involved in?}

In a construction project, the upstream supply chain consists of project client, main contractor and project management consultant while the downstream supply chain involves main contractor, subcontractors and labor, materials and equipment suppliers.

$\square$ Upstream supply chain

Downstream supply chain

\subsection{What was the collaboration that you experienced?}

$\square$ No collaboration (Traditional approach)

$\square$ Short-term collaboration

Long-term collaboration

\section{Supply chain relationship}

Please rate the supply chain relationship in the following areas by selecting Strongly Agree (SA), Agree (A), Disagree (D) or Strongly Disagree (SD).

Roles and responsibilities were well defined at the early stage

Mutual objectives were established between the parties

The parties trusted each other during the project

Joint efforts were made by the parties to work together

Communication between the parties was open and effective

Problem solving mechanism was effective

Benefits and risks were shared between the parties

Improvement was continuously made during the project

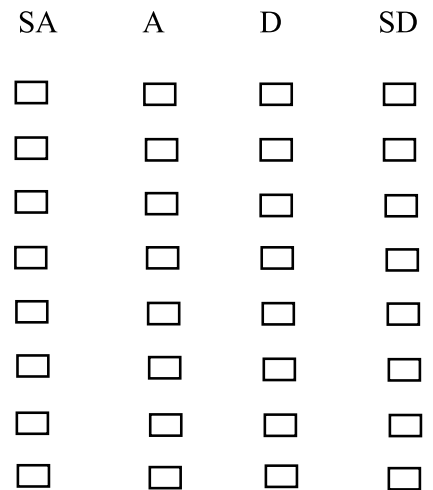

